\title{
Semen quality parameters, their inter-relationship and post-washing sperm attributes of Rhode I sland Red roosters
}

\author{
R. Richard Churchil1,2, P. Ezhil Praveena ${ }^{3}$ and Deepak Sharma1,4
}

1. Genome Mapping Laboratory, Central Avian Research Institute, Izatnagar, Bareilly, Uttar Pradesh, India; 2. Instructional Livestock Farm Complex, Veterinary College and Research Institute, Tamil Nadu Veterinary and Animal Sciences University, Orathanadu, Tamil Nadu, India; 3. Division of Aquatic Animal Health and Environment, Central Institute of Brackishwater Aquaculture, \# 75, Santhome High Road, R. A. Puram, Chennai, Tamil Nadu, India; 4. Division of Animal Genetics, Indian Veterinary Research Institute, Izatnagar, Bareilly, Uttar Pradesh, India.

Corresponding author: R. Richard Churchil, e-mail: churchil.r@tanuvas.org.in, PEP: epraveena@ciba.res.in, DS: ds7758@yahoo.co.in

Received: 20-10-2014, Revised: 19-11-2014 Accepted: 22-11-2014, Published online: 23-12-2014

doi: 10.14202/vetworld.2014.1117-1122. How to cite this article: Churchil RR, Praveena PE, Sharma D (2014) Semen quality parameters, their inter-relationship and post-washing sperm attributes of Rhode Island Red roosters, Veterinary World 7(12): 1117-1122.

\begin{abstract}
Aim: The present experiments were conducted (a) to evaluate the semen attributes of older Rhode Island Red (RIR) roosters and the inter-trait relationships, (b) to test sperm washing and storage duration suitable for gene transfer experiments.

Materials and Methods: The semen characteristics of older RIR roosters were studied, and Pearson correlation analysis was done to demonstrate the inter-trait relationships. Progressive motility and percent live sperms were tested at different post-washing intervals to identify suitable sperm processing conditions for gene transfer experiments.

Results: The volume, appearance score, initial motility, sperm count and percent live and abnormal spermatozoa were $0.38 \mathrm{ml}, 3.58,80.34 \%, 4.03 \times 10^{9}$ sperms $/ \mathrm{ml}, 83.18 \%$ and $4.52 \%$ respectively. Positive correlation was observed among appearance score, motility, live sperm and sperm count. Semen volume is negatively correlated with all the other characters except live sperms, whereas, percent abnormal sperms negatively associated with all the other traits. Significant $(\mathrm{p}<0.05)$ decrease in terms of motility and live sperm was recorded at 60 min post-washing.
\end{abstract}

Conclusion: The semen attributes of RIR roosters compares well with the other breeds of chicken. The appearance score can be used to assess fertility where microscopic evaluation facilities are limited. The sperm washing protocol tested in the experiment is suitable for gene transfer experiments.

Keywords: correlation, live sperm, post-washing motility, Rhode Island Red roosters, semen attributes.

\section{I ntroduction}

Semen evaluation by macroscopic and microscopic methods is the tool to evaluate male fertility in roosters [1]. Macroscopic parameters like color, consistency, appearance score and volume and the microscopic traits like concentration, initial motility, abnormal sperms and percent dead sperms are used in semen evaluation [2]. Among all, initial motility is considered as the single reliable characteristic of semen for identifying the fertilizing ability of the roosters [3].

The semen characteristics of avian species are different to a greater degree from that of mammals owing to the diverse physiology and anatomy like the intra-abdominal placement of testes and absence of accessory sex glands [4]. Moreover, the sperms of chicken are morphologically different from those of mammals [4] and very fragile to high environmental temperature and temperature fluctuations at cryopreservation [5]. The semen of avian species is highly concentrated with very minimal seminal plasma [4].

The semen quality in roosters was found to be varied among different genotypes like breed [6],

Copyright: The authors. This article is an open access article licensed under the terms of the Creative Commons Attributin License (http:// creative commons.org/licenses/by/2.0) which permits unrestricted use, distribution and reproduction in any medium, provided the work is properly cited. strain [7] and line [8]. The semen quality parameters reported for different breeds like White Leghorn [9], Plymouth Rock [8], Rhode Island Red (RIR) [10] and indigenous roosters [11] demonstrated high degree of variation. Age of roosters is also found to interact with semen quality parameters [12]. The environmental factors having influence on semen quality are climate [13], time of collection [14], frequency of collection [15] and nutrition [16]. The literature provides little information on the semen quality of RIR roosters and especially there is total paucity on semen attributes of older RIR roosters.

The individual sperm motility of indigenous roosters was found to have significant $(\mathrm{p}<0.01)$ positive correlation with live sperm, sperm concentration and sperm output in local chickens [17]. The interrelationship of semen quality parameters has been reported for broiler breeders [18], indigenous [11], hybrid [19] and a pool of several breeds [6], but little has been reported for RIR breed.

Seminal plasma of chicken has DNAse activity [20], therefore, its removal is necessary for sperm-mediated gene transfer experiments. The duration of DNA-sperm interaction in chicken is usually $<1 \mathrm{~h}$ in most of the sperm-mediated gene transfer experiments $[21,22]$. The viability of sperms at the 
time of insemination after washing and holding the washed cells for DNA-sperm interaction is the key factor in a successful production of transgenic birds by this method.

This study was aimed at investigating the semen quality parameters and their inter-relationship of 1-year-old RIR roosters and the post washing sperm quality, as the literature provide very little information on the subject.

\section{Materials and Methods \\ Ethical approval}

This study was conducted after approval by the research committee and Institutional Animal Ethics Committee.

A total of 20 adult healthy male birds of RIR breed kept at the layer farm of Central Avian Research Institute were utilized for this study. All the selected birds were positive respondents to abdominal massage method of semen collection irrespective of quality and quantity of semen. The birds were at 12 months of age during the study, housed in three-tier individual cages and kept under a standard management regime.

The semen was collected by abdominal massage method in the morning as per Lake and Stewart [23]. In the first experiment, the roosters were grouped randomly into four groups of five roosters each. One group of roosters was milked in a day and continued with other groups on daily basis in an order so that each group could be milked on every $5^{\text {th }}$ day. This was continued till four collections from each rooster were obtained and evaluated. The color, appearance score, volume, initial motility, sperm count and percent abnormal sperms were estimated from each collection. The average of four observations from each rooster was taken as the data for the particular rooster for further analysis.

The appearance of semen was scored $1-5$ by visual examination following the method described by McDaniel and Craig [24]. Semen volume was measured by a tuberculin syringe graduated up to an accuracy of $0.01 \mathrm{ml}$. The assessment of motility was conducted by examining a drop of semen on a warm slide under a microscope at $\times 100$. Motility was assessed on the basis of the percentage of sperm showing forward motion [23].

The sperm concentration was estimated as per the procedure suggested by Ax et al. [25] using a "Neubaur" hemocytometer and the concentration of spermatozoa was expressed in million $/ \mathrm{ml}$ or $\times 10^{9} / \mathrm{ml}$ of semen. To estimate the percentage of live and dead spermatozoa, the staining method described by Lake and Stewart [23] was adopted with some modifications. Briefly, a solution of nigrosine $(0.6 \mathrm{~g})$ and eosin $(0.16 \mathrm{~g})$ was made in $100 \mathrm{ml}$ sodium citrate solvent. $200 \mu \mathrm{l}$ of eosin-nigrosine stain was placed in a clean test tube, and semen was mixed well with the stain. After allowing the stain-semen mixture to stand for about $1 \mathrm{~min}$ at room temperature, a drop of it was placed on a clean and grease-free slide, a thin smear was prepared quickly and examined with a $100 \times$ oil immersion objective. A differential count on a sample of 300 spermatozoa (50 spermatozoa in each of 6 microscopic fields) was made categorizing the stained and partially stained sperms as 'dead' and unstained sperms as "live." The smears as prepared for live sperm estimation were used to study the percentage of abnormal spermatozoa [23]. A total of 200 spermatozoa were counted under the oil immersion objective of the microscope and classified as either normal or abnormal, and the total percent of abnormal spermatozoa was calculated.

In the second experiment, three aliquots of each $100 \mu \mathrm{l}$ for control (T1) and an aliquot of $500 \mu \mathrm{l}$ for sperm washing treatment (T2) were analyzed to study the effect of washing and storage time on sperm motility. The aliquots of $\mathrm{T} 1$ were allowed to stand at $4^{\circ} \mathrm{C}$ storage and from this nigrosine-eosin stained semen smears were prepared at 0,30 and 60 min to study percent live sperm. In T2, the semen sperms were washed as per the protocol optimized by the authors. Briefly, $500 \mu \mathrm{l}$ of semen was centrifuged at $3000 \mathrm{rpm}$ for $5 \mathrm{~min}$ at $5^{\circ} \mathrm{C}$ to remove the seminal plasma. The sperm pellet was then dispersed homogenously in three initial volumes $(1500 \mu \mathrm{l})$ of CARI semen extender [26]. The sperm cells suspended in semen extender were then centrifuged, and the supernatant containing contaminants like fecal matter, uric acid and red blood cells were discarded. The sperm cells were washed once more, and the final sperm pellet was dispersed in semen extender in the final volume of $1000 \mu \mathrm{l}$. After washing the sperms swiftly for three times, three aliquots of $100 \mu \mathrm{l}$ were allowed to stand at $4^{\circ} \mathrm{C}$ for analysis one each at 0,30 and $60 \mathrm{~min}$ post-washing for motility and live sperms by the methods described earlier. This was replicated 6 times in both the treatments to get mean values.

Statistical analysis to extract the descriptive statistics on different quality characteristics was carried out by SPSS computer program provided by SPSS Inc., USA. The effect of sperm washing on various quality parameters at different post-washing periods was performed by the SPSS program using ANOVA. When the F values were significant $(p<0.05)$, Duncan's multiple range test was performed. Student's t-test was carried out to find the differences in motility and live sperms between control and washed semen. The correlation coefficients between different quality parameters and regression coefficients to explain the trend in motility and live sperms on storage were also extracted from the data using SPSS program.

\section{Results}

The examination of color of all the 80 semen samples revealed that majority of the ejaculates were thick white or chalky white $(62.50 \%)$ followed by yellow or transparent yellow (17.50\%), creamy white $(13.75 \%)$ and thin white or watery $(6.25 \%)$. The 
descriptive statistics on volume, appearance score, initial motility, sperm count and percent live and abnormal spermatozoa were $0.38 \mathrm{ml}, 3.58,80.34 \%$, $4.03 \times 10^{9}$ sperms $/ \mathrm{ml}, 83.18 \%$ and $4.52 \%$ respectively (Table-1).

The correlation co-efficient values between various quality parameters are given in Table-2. The results proved that the semen volume was negatively correlated with all the other characters except live sperms with coefficient values of volume with initial motility and sperm count assuming significantly $(\mathrm{p}<0.05)$ higher degree. The appearance score had a very strong $(\mathrm{p}<0.01)$ positive association with vital fertility parameters such as motility, live sperm and sperm count. The initial motility was found to have a positive correlation of very high degree $(p<0.01)$ with live sperm and sperm count. The abnormal sperms had a negative correlation of insignificant ( $>0.05)$ scale with other characters like volume, appearance score, initial motility, live sperms, and sperm count.

The changes on motility and live sperms resulted from washing and storage of spermatozoa is presented in Table-3. There was no significant difference noticed in terms of motility and live sperms between different post-washing storage periods in unwashed control semen (T1). Significant difference in terms of motility $(p<0.05)$ and live sperm $(p<0.01)$ was recorded between storage periods in the washed sperms (T2) with 60 min storage resulting in significant decrease of both motility and live sperm compared with 0 and $30 \mathrm{~min}$ storage. The regression analysis revealed a significant $(\mathrm{p}<0.05)$ decline of live sperms on storage in control as well as washed sperms. Student's t-test conducted to find a treatment effect revealed that washing had resulted in significant $(p<0.05)$ decrease in motility and live sperms at all the post-washing time intervals except motility at $30 \mathrm{~min}$.

\section{Discussion}

The examination of color of the semen samples revealed that most of the samples $(86.25 \%)$ fell into the categories of thick white/chalky white or creamy white, which are considered as suitable for insemination. The age of the roosters may be taken as the contributing factor for the yield of yellow or transparent yellow or thin white or watery semen from a considerable number of roosters under study.

The volume of semen per ejaculate in the study agreed with the findings of Shanmugam et al. [27] in 65 weeks old RIR roosters $(0.36 \mathrm{ml})$ but lower than the volume reported at a younger age of 42 weeks

Table-1: The descriptive statistics on different quality characteristics of semen of RIR roosters.

\begin{tabular}{lcccccc}
\hline Parameters & $\begin{array}{c}\text { Volume } \\
(\mathbf{m l})\end{array}$ & $\begin{array}{c}\text { Appearance } \\
\text { score }\end{array}$ & $\begin{array}{c}\text { I nitial } \\
\text { motility }(\%)\end{array}$ & $\begin{array}{c}\text { Sperm count } \\
(\times \mathbf{1 0} / \mathbf{~ m l )}\end{array}$ & $\begin{array}{c}\text { Live spermatozoa } \\
(\mathbf{\%})\end{array}$ & $\begin{array}{c}\text { Abnormal } \\
\text { spermatozoa (\%) })\end{array}$ \\
\hline Mean \pm SE & $0.38 \pm 0.02$ & $3.58 \pm 0.25$ & $80.34 \pm 3.37$ & $4.03 \pm 0.22$ & $83.18 \pm 2.47$ & $4.52 \pm 10$ \\
Minimum value & 0.21 & 0 & 30 & 1.52 & 53 & 0.75 \\
Maximum value & 0.78 & 5 & 95 & 5.63 & 98 & 26.31 \\
CV (\%) & 25.37 & 30.11 & 17.91 & 23.45 & 12.68 & 46.15 \\
\hline
\end{tabular}

$\mathrm{CV}=$ Coefficient of variation, $\mathrm{SE}=$ Standard error, $\mathrm{RIR}=$ Rhode Island Red

Table-2: Correlation matrix of different semen quality characters of RIR roosters.

\begin{tabular}{|c|c|c|c|c|c|c|}
\hline Characters & Volume & $\begin{array}{l}\text { Appearance } \\
\text { score }\end{array}$ & $\begin{array}{l}\text { I nitial } \\
\text { motility }\end{array}$ & $\begin{array}{c}\text { Live } \\
\text { sperms }\end{array}$ & $\begin{array}{c}\text { Sperm } \\
\text { count }\end{array}$ & $\begin{array}{c}\text { Abnormal } \\
\text { spermatozoa }\end{array}$ \\
\hline Volume & 1.00 & & & & & \\
\hline Apparence score & -0.26 & 1.00 & & & & \\
\hline I nitial motility & $-0.47 *$ & $0.76 * *$ & 1.00 & & & \\
\hline Live sperms & 0.00 & $0.73 * *$ & $0.86 * *$ & 1.00 & & \\
\hline Sperm count & $-0.49 *$ & $0.89 * *$ & $0.63 * *$ & $0.46 *$ & 1.00 & \\
\hline Abnormal spermatozoa & -0.11 & -0.37 & -0.35 & -0.33 & -0.26 & 1.00 \\
\hline
\end{tabular}

$\mathrm{RIR}=$ Rhode Island Red, **Significant $(p<0.01), *$ Significant $(p<0.05)$

Table-3: The influence of washing of spermatozoa and duration of storage on motility and live sperms of RIR roosters.

\begin{tabular}{|c|c|c|c|c|c|c|c|}
\hline \multirow[t]{2}{*}{ Parameters } & \multirow[t]{2}{*}{ Treatments } & \multicolumn{3}{|c|}{ Duration of storage } & \multirow[t]{2}{*}{ Overall } & \multirow[t]{2}{*}{ F value } & \multirow{2}{*}{$\begin{array}{l}\text { Regression } \\
\text { coefficient }\end{array}$} \\
\hline & & $0 \mathrm{~min}$ & $30 \mathrm{~min}$ & $60 \mathrm{~min}$ & & & \\
\hline$(\%)$ & $\begin{array}{l}\text { T1 - Control } \\
\text { T2- Washed sperms } \\
\text { Overall } \\
\text { t value }\end{array}$ & $\begin{array}{c}88.20 \pm 1.70 \\
83.38 \pm 1.15^{\times} \\
85.79 \pm 1.08 \\
5.51^{*}\end{array}$ & $\begin{array}{c}86.39 \pm 1.71 \\
82.42 \pm 0.98^{x y} \\
84.40 \pm 1.02 \\
4.05^{\mathrm{NS}}\end{array}$ & $\begin{array}{c}83.62 \pm 1.42 \\
79.82 \pm 1.15^{y} \\
81.72 \pm 0.95 \\
4.32 *\end{array}$ & $\begin{array}{c}86.07 \pm 0.95 \\
81.87 \pm 0.65 \\
83.97 \pm 0.60 \\
13.26 * *\end{array}$ & $\begin{array}{l}2.03^{N S} \\
2.83^{*} \\
4.10^{*}\end{array}$ & $\begin{array}{l}-2.29^{\mathrm{NS}} \\
-1.78^{\mathrm{NS}} \\
-2.04^{\mathrm{NS}}\end{array}$ \\
\hline Live sperms (\%) & $\begin{array}{l}\text { T1 - Control } \\
\text { T2 - Washed sperms } \\
\text { Overall } \\
\text { t value }\end{array}$ & $\begin{array}{c}84.30 \pm 1.72 \\
79.13 \pm 1.24^{\times} \\
81.72 \pm 1.12 \\
5.97^{*}\end{array}$ & $\begin{array}{c}82.10 \pm 1.81 \\
76.37 \pm 1.51^{x y} \\
79.24 \pm 1.25 \\
5.94 *\end{array}$ & $\begin{array}{c}79.32 \pm 1.55 \\
72.92 \pm 1.15^{y} \\
76.12 \pm 1.08 \\
11.01 * *\end{array}$ & $\begin{array}{l}81.91 \pm 1.00 \\
76.14 \pm 0.81 \\
79.02 \pm 0.69 \\
20.11 * *\end{array}$ & $\begin{array}{l}2.17^{\mathrm{NS}} \\
5.66^{* *} \\
5.90^{* *}\end{array}$ & $\begin{array}{l}-2.49 * \\
-3.11^{*} \\
-2.80^{*}\end{array}$ \\
\hline
\end{tabular}

$x, y$ Mean values bearing different superscript in a row do not differ significantly $(p<0.05)$, *Significant $(p<0.05)$,

$* *$ Significant $(p<0.01)$, NS $=$ Not significant 
$(0.48 \mathrm{ml})$ in the same population. In general, earlier reports revealed higher values of 0.43 [16], 0.51 [28] and 0.7 and $0.8 \mathrm{ml}$ [29] in younger RIR roosters evaluated between 28 and 35 weeks of age. When compared with different types of chicken, the volume of ejaculate obtained in this study was intermediate, which was lower than that of broiler breeders [18] but higher than that of layer breeders [7,9] and native chicken [17].

The appearance score value of 3.58 observed in the study agreed with the report of Murugesan et al. [7] in IWH strain of White Leghorn aged between 62 and 68 weeks, but intermediate with the highly variable values reported in the literature in naked neck (3.94) and dwarf (3.84) genetic lines [30] and Beijing-You chickens (2.40) [11]. This parameter has not been studied adequately in RIR males and a lone study [10] reports a lower value of 2.96 .

The initial motility observed in the study was similar to the findings of Uysal et al. [29] in two RIR lines ( 84.4 and $85.0 \%$ ) at 35 weeks of age. The wide variations in motility of $45 \%$ [27], 66.8\% [28] and $73.83 \%$ [16] reported in the literature could be ascribed to the difference in strain, age and geographical location.

The sperm count (billion cells $/ \mathrm{ml}$ ) observed in the study was in line with the findings of Shanmugam et al. [27], who observed 4.8 and 3.57 respectively in 42 and 65 weeks of age in Dahlem Red strain of RIR. The other earlier experiments conducted in RIR roosters aged between 28 and 35 weeks demonstrated lower values of 3.3 and 3.2 [29] or very low values of 0.75 [28] and 1.97 [16]. The earlier reports on other breeds $[6,7,9,30]$, and hybrids [18,19] also demonstrated a high degree of variation with the values ranging between 1.17 [11] and 8.9 [8].

The percent live sperms of RIR roosters subjected to this study compares favorably with the previous reports on the same breed [10,29]. In contrast, Shanmugam et al. [27] reported higher values of 91.21 and $92.12 \%$ from RIR roosters of 42 and 65 weeks of age. The literature provides evidence for a wide variation of live spermatozoa ranging from $58.88 \%$ [7] to $86.6 \%$ [17] in older roosters of other breeds.

The present value on abnormal spermatozoa fell within the range of $3.2 \%$ and $6.13 \%$ reported by Uysal et al. [29] and Shanmugam et al. [27] respectively in RIR roosters. However, evidence for higher level of abnormal spermatozoa in RIR roosters (11.07\%) by Kabir et al. [10] and other breeds (16.58\%) by Galal [31] is also available in the literature.

The higher coefficient of variation observed in the study, especially in volume, appearance score, abnormal spermatozoa and sperm count reflects wide variation in the data. The age of the birds may be a contributor for this variation that is also reflected in minimum and maximum values.

The strong negative association between semen volume and sperm count leads the authors to hypothesize that the semen samples of higher volumes were diluted by the transparent lymphatic fluid extraction while collection. This further strengthen the earlier finding of agonistic effect of lymphatic fluid on sperm motility [32] as the present study also revealed a strong $(\mathrm{p}<0.05)$ negative association between semen volume and motility. The lower motility in semen ejaculates of higher volume may be ascribed to the presence of more lymphatic fluid. The appearance score having a very strong $(\mathrm{p}<0.01)$ positive association with other vital fertility parameters is in expected line and consistent with earlier observations [33]. This finding tends to have vast field applications were microscopic evaluation facilities are limited. Initial motility was found to have a positive correlation of very high degree $(p<0.01)$ with live sperm and sperm count as reported earlier [17]. This strengthens earlier suggestions [3] of considering motility as the single important semen characteristic in assessing the fertility of the rooster. It is also evident from the study that ejaculates having higher sperm count ought to have a higher percent live sperms as these parameters have high $(p<0.05)$ degree of association on the positive scale. Though not significant ( $p>0.05)$, the percent abnormal sperms, a contributing factor for poor fertility having negative association with all the other characters such as volume, appearance score, initial motility, live sperms and sperm count which are contributory for good fertility is well in the expected line.

The washed spermatozoa generally had lower motility and percent live sperms at any point of storage. Earlier data [34] has also shown that washing of spermatozoa was detrimental to their viability. The present study revealed that washing of spermatozoa resulted in significant $(\mathrm{p}<0.05)$ deterioration of motility and percent live sperms at 60 min post-washing. Despite the decline observed in the study, the semen washed as per the protocol optimized by the authors described earlier had more than $70 \%$ motility and live sperms at 60 min post-washing, indicating its suitability for artificial insemination. The duration of exogenous DNA-sperm interaction in sperm-mediated gene transfer experiments in chicken is normally $1 \mathrm{~h}$ or less $[21,22]$. Therefore, the sperm washing procedure followed in this study can be considered as optimum for the purpose.

\section{Conclusion}

The semen attributes of RIR roosters compares well with the other breeds of chicken. The age of the roosters may be taken as the contributing factor for a considerable number of roosters yielding semen of inferior color and consistency. The lower motility in semen ejaculates of higher volume may be ascribed to the presence of more lymphatic fluid. The abnormal sperms, a contributing factor for poor fertility having negative association with all the other characters like volume, appearance score, initial motility, live 
sperms and sperm count which are contributory for good fertility is well in the expected line. Despite the decline observed on storage, the semen washed as per the protocol optimized by the authors had more than $70 \%$ motility and live sperms at 60 min post-washing, indicating its suitability for sperm-mediated gene transfer experiments.

\section{Authors' Contributions}

RRC carried out the research work, semen analysis and revision of the manuscript. PEP assisted in data processing and manuscript preparation. DS designed the research work and provided guidance for conducting experiments. All authors read and approved the final manuscript.

\section{Acknowledgments}

Authors are thankful to Central Avian Research Institute, Bareilly, UP, India for providing facilities to carry out this work. The authors are also thankful to the Indian Council of Agricultural Research (ICAR) for providing necessary funds for the study.

\section{Competing I nterests}

The authors declare that they have no competing interests.

\section{References}

1. Peters, S.O., Omidiji, E.A., Ikeobi, C.O.N., Ozoje, M.O. and Adebambo, O.A. (2004) Effect of naked neck and frizzled genes on egg traits, fertility and hatchability in local chicken. In: Self-sufficiency of animal protein in Nigeria. Proceedings of the $9^{\text {th }}$ Annual Conference of Animal Science Association of Nigeria, Ebonyi State University, Abakaliki, Nigeria, September 13-16 2004. p262-264.

2. Moce, E. and Graham, J.K. (2008) In vitro evaluation of sperm quality. Anim. Reprod. Sci., 105: 104-118.

3. Charms, F.L. (1969) Variations in semen quality and relationship of semen quality fertility in turkeys. Poult. Sci., 47(3): 746-754.

4. Etches, R.J. (1996) The male. In: Reproduction in Poultry. Wallingford, UK: CAB International. p208-233.

5. Graham, E.F. (1978) Fundamentals of the preservation of spermatozoa. In: The Integrity of Frozen Spermatozoa. National Academy of Sciences, Washington D.C. p228.

6. Peters, S.O., Shoyebo, O.D., Ilori, B.M., Ozoje, M.O., Ikeobi, C.O.N. and Adebambo, O.A. (2008) Semen quality traits of seven strain of chickens raised in the humid tropics. Int. J. Poult. Sci., 7: 949-953.

7. Murugesan, S., Matam, N., Kulkarni, R., Bhattacharya, T.K. and Chatterjee, R.N. (2013) Semen quality in white leghorn chicken selected for egg production traits. Turk. J. Vet. Anim. Sci., 37: 747-749.

8. Tarif, A.M., Bhuiyan, M.M.U., Ferdousy, R.N., Juyena, N.S. and Mollah, M.B.R. (2013) Evaluation of semen quality among four chicken lines. IOSR J. Agric. Vet. Sci., 6: 7-13.

9. Elagib, H.A.A., Msharaf, N.A., Makawi, S.A. and Mohamed, H.E. (2012) The effects of age and season on semen characteristics of White Leghorn roosters under Sudan conditions. Int. J. Poult. Sci., 11: 47-49.

10. Kabir, M., Oni, O.O. and Akpa, G.N. (2007) Osborne selection index and semen traits interrelationships in Rhode Island Red and White breeder roosters. Int. J. Poult. Sci., 6: 999-1002.

11. Hu, J., Chen J.L., Wen, J., Zhao, G.P., Zheng, M.Q., Liu, R.R., Liu, W.P., Zhao, L.H., Liu, G.F. and Wang, Z.W.
(2013) Estimation of the genetic parameters of semen quality in Beijing-You chickens. Poult. Sci., 92(10): 2606-2612.

12. Kelso, K.A., Cerolini, S., Noble, R.C., Sparks, N.H.C., Speake, B.K. (1996) Lipid and antioxidant changes in semen of broiler fowl from 25 to 60 weeks of age. J. Reprod. Fertil., 106(2): 201-206.

13. Saeed, J.M. and Al-Soudi, K.A. (1975) Semen quality traits of seven strains of chickens raised in the humid tropics. $J$. Anim. Vet. Adv., 7: 848-849.

14. Egbunike, C.N. and Oluyemi, J.A. (1979) Comparative studies of the reproductive capacity of the Nigerian and Exotic poultry breeds. Niger. J. Anim. Prod., 6: 47-51.

15. Riaz, A., Aleem, M., Ijaz, A., Saeed, M.A., Latif, A (2004) Effect of collection frequency on the semen quality of broiler breeder. Br. Poult. Sci., 45(6): 823-827.

16. Kabir, M., Oni, O.O., Akpa, G.N., Adeyinka, I.A. and Rekwot, P.I. (2007) Effects of underfeeding on semen quality of Rhode Island roosters. Pak. J. Biol. Sci., 11: 986-988.

17. Bah, G.S., Chaudhari, S.U.R. and Al-Amin, J.D. (2001) Semen characteristics of local breeder roosters in the Sahel region of Nigeria. Rev. Elev. Med. Vet. Pays Trop. (Paris), 54: 153-158.

18. Modupe, O., Livinus, A.C. and Ifeanyi, N.B. (2013) Semen quality characteristics and effect of mating ratio on reproductive performance of Hubbard broiler breeders. J. Agric. Sci., 5: 154-159.

19. Chauhan, P.M., Suthar, B.N., Nakhashi, H.C., Sharma, V.K., Sutaria, T.V. and Parmar, V.R. (2012) Studies on certain biophysical attributes of Gramapriya hybrid rooster semen. Wyamba J. Anim. Sci., 4: 629-634.

20. Sato, F., Soh, T., Hattori, M. and Fujihara, N. (2003) Evaluation of deoxyribonuclease activity in seminal plasma of ejaculated chicken semen. Asian J. Androl., 5: 213-216.

21. Churchil, R.R., Gupta, J., Singh, A. and Sharma, D. (2011) Exogenous DNA internalization by sperm cells is improved by combining lipofection and restriction enzyme mediated integration. Br. Poult. Sci., 52(3): 287-291.

22. Samoylov, A.V., Kesyan, A.Z. and Suraeva, N.M. (2013) Development of transgenic chicken with a gene of human granulocyte colony-stimulating factor using sperm-mediated gene transfer. Biol. B., 40: 419-422.

23. Lake, P.E. and Stewart, J.M. (1978) Artificial insemination in poultry. Bulletin, Ministry of Agriculture, Fisheries and Food, Her Majesty's Stationery Office, Belfast, Great Britain. p34.

24. McDaniel, G.R. and Craig, J.V. (1959) Behaviour traits, semen measurements and fertility of White Leghorn males. Poult. Sci., 38: 1005-1014.

25. Ax, R.L., Dally, M., Didion, B.A. and Lenz, R.W. (2000) Semen evaluation. In: Hafez, B. and Hafez, E.S.E., editors. Reproduction in Farm Animals. $7^{\text {th }}$ ed. Lippincott Williams \& Wilkins, Philadelphia, p365-375.

26. Mohan, J, Moudgal, R.P. and Singh, R.V. (2000) A process for preparation of a new and simple diluents for chicken semen. Patent No. 191190.

27. Shanmugam, M., Vinoth, A., Rajaravindra, K.S. and Rajkumar U. (2014) Evaluation of semen quality in roosters of different age during hot climatic condition. Anim. Reprod. Sci., 145(1-2): 81-85.

28. Machal, L. and Krivanek, I. (202) Indicators of semen quality of roosters of three parental layer lines and specific conductivity of the semen. Acta Vet. Brno, 71: 109-116.

29. Uysal, O., Demir, Z., Cebi, C., Demirtas, S.E., Tırpan, M.B., Tunca, M., Kamanli, S. (2011) Evaluation of semen quality in pure lines of the brown laying roosters in Poultry Research Institute. Kafkas Üniv. Vet. Fak. Derg., 17: 655-658.

30. Shanmugam, M, Rajkumar, A.U., Reddy, M.R. and Rao, S.V.R. (2012) Effect of age on semen quality in naked neck and dwarf chicken under tropical climatic conditions. Anim. Prod. Sci., 52: 964-968.

31. Galal, A. (2007) Predicting semen attributes of naked neck 
and normally feathered male chickens from live performance traits. Int. J. Poult. Sci., 6: 36-42.

32. Froman, D. (2003) Deduction of a model for sperm storage in the oviduct of the domestic fowl (Gallus domesticus). Biol. Reprod., 69(1): 1248-1253.

33. Santiago-Moreno, J., Lopez-Sebastian, A., Castano, C., Coloma, M.A., Gomez-Brunet, A., Toledano-Diaz, A., Prieto, M.T. and Campo, J.L. (2009) Sperm variables as predictors of fertility in Black Castellana roosters; use in the selection of sperm donors for genome resource banking purposes. Span. J. Agric. Res., 7: 555-562.

34. Collares, T., Campos, V.F., deLeon, P.M.M., Cavalcanti, P.V., Amaral, M.G., Dellagostin, O.A., Deschamps, J.C. and Seixas, F.K. (2011) Transgene transmission in chickens by sperm-mediated gene transfer after seminal plasma removal and exogenous DNA treated with dimethylsulfoxide or N,N-dimethylacetamide. J. Biosci., 36(4): 613-620.

$* * * * * * * *$ 